\title{
Railway infrastructures sustainable interventions: Proposal for a Cost-Benefit Analysis application
}

\author{
Paula Couto ${ }^{1, *}$, Filipa Salvado ${ }^{1}$, and Maria João falcão Silva ${ }^{1}$ \\ ${ }^{1}$ LNEC, Buildings Department, Av. Brasil, 101, 1700-066 Lisboa, Portugal
}

\begin{abstract}
The decision to intervene in Railway Infrastructures (RI) in a sustainable way is complex, because the involved costs require different assessment levels, given their relevance to all stakeholders in decisionmaking, and are not always easily quantifiable. Following recent decisions of the EU, it is urgent to carry studies to support RI sustainable interventions. In this context, the use of methodologies based on CostBenefit Analysis (CBA) contributes positively to base decisions on RI investment projects. CBA is a methodology to assess the net economic impact of a public investment project and can be used for a variety of interventions. $\mathrm{CBA}$ is based on the conversion to monetary values of all costs and benefits, even when they are intangible. The purpose of a CBA is to evaluate if a project is feasible from the point of view of social welfare through the algebraic sum of their costs and benefits discounted over time. This paper presents a framework for the assessment of RI sustainable projects based on CBA, which integrates the development of community policies and financial instruments. It aims to provide technical support and contribute to the reflection about co-financing rates modulation.
\end{abstract}

\section{Introduction}

The Cost-Benefit Analysis (CBA) of investment projects is explicitly required by the new European Union regulations governing the Structural Funds, the Cohesion Fund and the Instrument for Structural Pre-Accession, in the case of projects whose budgets exceed, respectively, 50, 10 and 5 million euro. The purpose of a CBA is to assess whether a project is viable from the standpoint of social welfare through the algebraic sum of its discounted costs and benefits over time. The ACB makes possible to determine whether future benefits will be sufficient to justify the actual costs of investment projects, based on the conversion into monetary amounts of all costs and benefits, and their corrections, even when they are intangible. As in other sectors of activity and with other types of projects, the decision to intervene in investment projects in railway infrastructure is complex, since the associated costs require different levels of evaluation, the relevance for stakeholders is great in the decision-making process, and in most situations are not easily quantifiable. The application

\footnotetext{
* Corresponding author: mjoaofalcao@,lnec.pt
} 
of $\mathrm{CBA}$ to interventions in railway infrastructure requires rigor and methodological consistency [1-5]. The present article intends to frame the CBA with a view to the implementation in investment projects in railway infrastructures to promote actions in the level of its rehabilitation and regeneration. In this sense, its importance and potentialities will be highlighted for various actors in the decision-making process, as well as a simple example applicable to interventions in railway infrastructures. Some preliminary remarks, as well as prospective future developments, will be presented and discussed.

\section{Cost-benefit analyses: Theoretical framework}

The Cost-Benefit Analysis (CBA) was first proposed by the French engineer Jules Dupuit (1804-1866) [6], who used the method to quantify the usefulness of public works. Later on, and under the impulse of the British economist Alfred Marshall, CBA became a synonym for public works projects [7], having since been applied in the analysis of projects in different areas. A CBA is a method for assessing the net economic impact of an investment project and can be used for a variety of interventions [1].

This type of analysis translates into a systematic procedure for the evaluation of decisions that have a direct impact on society, allowing to study the feasibility of projects and evaluate their impacts based on the comparison of costs and benefits over a certain time horizon.

The purpose of a CBA is to identify and assign a monetary value to all possible impacts in order to determine the costs and benefits of an activity or project; then the results are aggregated (net benefits) and conclusions are drawn on whether the project is desirable and worthwhile to execute. [8]

In addition to the above, a CBA is based on the reduction in monetary values of all costs and benefits, even when these are intangible, undergoing several corrections, namely: (i) price distortions; ii) monetization of non-monetary impacts; iii) inclusion of indirect effects; and iv) use of a social updating rate different from the financial one.

The CBA is justified when economic activity gives rise to social costs or benefits that exceed private ones [4-5, 9]. The main advantage of CBA when compared to other evaluation techniques is that the external effects and price distortions observed are also considered [10-11]. The CBA model to support the development of investment projects, which may be applicable to infrastructure projects, is structured in different PHASES, as shown in Figure 1.

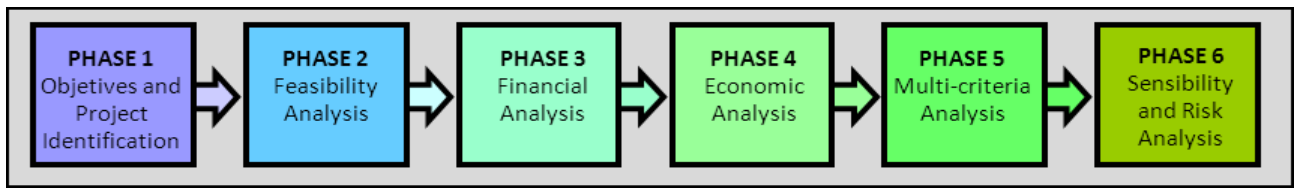

Figure 1. Cost-benefit methodology for investment projects.

\section{Application of cost-benefit analysis to investment projects in railway infrastructures}

\subsection{Objectives and project identification}

In investment project in railway infrastructures it is important to identify ex-ante the main parameters that determine the objectives, considering that investment projects in the area of railway infrastructure have very specific objectives, such as improvement of travel 
conditions for goods and passengers both inside the study area and to and from the study area (accessibility) as well as the improvement of the quality of the environment and the well being of the served population [4]. A good starting point for briefly, but clearly and unequivocally, identifying the infrastructure is to state the typology of the investments; the functional characteristics of the investments as well as the type of services, which should be coherent with the objectives of the investment. Concerning the typology of the investments in railway projects is important to consider: i) new infrastructures to satisfy increasing demand; ii) completion of existing networks (missing links); iii) extension of existing infrastructure; iv) renovation of existing infrastructure; v) investment in safety measures on existing links or networks; vi) improved use of the existing networks (i.e. better use of under-utilised network capacity); vii) improvement in intermodality (interchange nodes, accessibility to other transport infrastructures); viii) improvement in networks interoperability; ix) improvement in the management of the railway infrastructure. Regarding the functional characteristics of the railway investments should be considered: i) increasing capacity of existing networks; ii) reducing congestion; iii) reducing externalities; iv) improving accessibility to peripheral regions; v) reducing transport-operating costs. Finally, considering the types of services propose it is important to guarantee infrastructures (railway) for: i) densely populated areas; ii) long distance travel demand; iii) freight transport; iv) passenger transportation.

\subsection{Feasibility analysis}

The feasibility analysis of an investment project in the area of tourism does not only refer to the verification of the possibility of implementing the various specialties of the project, but also involves the consideration of aspects related to marketing, management, performance analysis, identification of socio-economic objectives, etc. [12]. The estimate of the existing demand and its forecast into the future is a complex and critical task that often consumes a substantial part of the resources allocated to the feasibility study.

The demand/capacity ratio of the new infrastructure will be analysed for any project alternative which is considerated. This will be based on: i) the service levels of the infrastructure (flows on railway, passengers on transport systems, etc.); ii) the travel times and costs for users (disaggregated by gender and origin typology); iii) transport indicators (passengers $\mathrm{km}$ and railways $\mathrm{km}$ for passengers, tons $\mathrm{km}$ and railways $\mathrm{km}$ for goods; iv) the safety levels in the new infrastructure or in the new configuration of the existing one.

The analysis of alternative project solutions is critical. After having defined the reference solution (to do nothing) and analysed the critical aspects in terms of a demand/capacity ratio it is necessary to identify all promising technical alternatives on the basis of physical circumstances and available technologies. The main risk of distorting the evaluation is the risk of neglecting relevant alternatives, in particular low-cost solutions (managing and pricing solutions, infrastructural interventions which are considered as not "decisive" by designers and promoters, etc.).

It is necessary to make sure that the project includes all the works required for its functionality (for example the links to the existing networks, technological plants, etc.) as well as all the relevant costs of each alternative, that the estimates of implementation costs and times are realistic and prudent, mainly in the projects which may have a special significance for the local community.

\subsection{Financial analysis}

The analysis will be generally conducted from the viewpoint of the railway infrastructure owners (generally managers but not necessarily operators of the railway infrastructure). If 
required, it may be carried out for the owners and the operators, first separately and then in a consolidated way. Financial investment costs, including the expenses for renewals and extraordinary maintenance operations as well as operating costs (including the ordinary maintenance costs of planned works and those related to tolling) are estimated during the technical analysis, disaggregated by the type of works into which the intervention may be broken down and allocated all over the time and on the basis of elementary cost components (labour force, materials, carriage and freightage) so as to enable the subsequent application of the conversion factors from financial into economic costs. Financial inputs will be represented by the proceeds from the tolls and/or tariffs applied for the sale of welldefined services.

The estimate of proceeds should be consistent with the hypotheses which have been put forward for the evolution and elasticity of demand. The financial analysis of non-rated infrastructures will show the net present cost at the public finance's expense. As to the recourse to private financing, it is necessary to pay attention to any inefficiency which may result from the adoption of pricing criteria other than those related to marginal social costs. It has been assumed that the residual value of the infrastructure will amount to $50 \%$ of the initial value at the end of the analysis period, except for the expropriations whose residual value will be equal to the initial value. Proceeds will derive from the traffic using the new motorway. National fares will be applicable. The internal financial rate of return is considered as $0.5 \%$.

\subsection{Economic analysis}

For economic investment and operating costs, if market prices are deemed to reflect the shortage of resources, it will be necessary to eliminate transfers from the financial costs by applying a conversion factor to each elementary cost component (labour force, materials, carriage and freightage) and by taking tax burdens into account. If market prices are not deemed to reflect the shortage of resources for some components, it will be necessary to apply shadow prices to correct costs [14].

Benefits traditionally result from the variations in the area underlying the transport demand curve (Consumer Surplus) as well as from the variations in economic costs (the costs of resources, including external costs). When calculating the benefits, it is recommended to make a distinction between the benefits for existing traffic (for example a time and cost reduction as a result of a speeding up process), the benefits of the traffic diverted from other modes (variations in costs, times and externalities as a result of the passage from a mode to another one) and the benefits of generated traffic (social surplus variation). A series of goods which have no market should be given great importance in the economic evaluation of any project which may be related to transport infrastructure, i.e. the value of time (time benefits often represent the most relevant part of the benefits of transport projects), environmental effects (generally depend upon the travel distances and exposure degrees to polluting emissions, except for $\mathrm{CO}_{2}$ representing a "global" pollutant.

In order to monetise the environmental effects, in the absence of local values, it is possible to apply to the "physical" estimates of pollutants the "shadow prices"), the value of avoided accidents should be referred to the average dangerousness levels by transport mode.

\subsection{Multicriteria analysis}

The main challenge identified in investment projects in railway infrastructures corresponds to the choice of the most profitable intervention (higher rate of return), that is, that allows a greater return in a shorter period of time. Account should be taken of: i) the continued 
operation of the infrastructure (for example, if the interventions are for rehabilitation); ii) preservation of the safety and integrity of its users / occupiers (e.g. in rehabilitation interventions); iii) minimization of losses (human and material) during the intervention.

In this respect, it is possible to identify objectives of a technical and economic nature. The technical objectives are: i) to minimize the vulnerability of the structure; ii) ensure the functionality / operation of the infrastructure; and iii) minimize the complexity of the intervention. The main economic objective is to minimize the total cost of the intervention. This key point of decision making related to the total cost of the intervention should be considered separately from the other objectives.

The main concern is its use in the context of an approach based on the principle of costbenefit maximization. It is considered to be a determining factor for the success of investment projects in the field of railway infrastructure, the analysis of personnel and operating costs (maintenance, operation, use) as well as long-term price dynamics [13].

\subsection{Sensibility and risk analysis}

Sensitivity analysis consist in examining the extent to which the profitability indicators for the various alternatives vary with some key variables in order to check the soundness of the achieved results and the ranking of any tariff alternative as well as to identify the riskiest areas. Because of their criticality it is advisable to carry out sensitivity analysis at the money values which have been assigned to the goods without any market. Other sensitivity analysis may be focussed, for example, on investment and operating costs or on the expected demand, in particular the generated traffic, [15].

\section{Final remarks}

CBA is a very useful tool in the evaluation and selection of hypotheses of investment projects, but that requires rigor and methodological coherence. The CBA methodology presented is applicable to the resolution of complex problems, proving to be of great use to the decision agent, not only regarding its decision-making, but also in structuring and understanding the problem.

The application of the CBA to investment projects presents an added value, both technically and scientifically, which allows: i) to express a judgment on the economic and social suitability of these projects; (ii) to establish a comparison between different design alternatives; and iii) encourage the practice of identifying and accounting for economic costs and benefits, even if not immediately convertible into monetary units.

The structure of the problem turns out to be the most complex stage given the number of specific and operational objectives that can be defined by the actors in the decisionmaking process. In the application of the model, difficulties in distinguishing the difference in attractiveness between some of the levels of performance of the various criteria appear in certain circumstances. To overcome this issue, the attribution of judgments of differences in attractiveness, proves to be of great utility in obtaining a coherent model and contributing to the decision process.

The final evaluation of an investment project for railway infrastructures sustainable interventions should be conducted in the same way as the assessment of the options, with identical procedures, including the implementation of a CBA based on actual data rather than forecasts. In this way, it is possible to introduce, in future similar projects and decision-making processes, the experience and acquired information.

Presently are being developed some applications of the methodology presented in order to support railway infrastructures sustainable interventions. The results obtained will be object of future analysis and publications. 


\section{References}

[1] W. Ward, B. Deren, E. D'Silva, The economics of project analysis: A practitioner's guide. EDI technical materials, World Bank (1991).

[2] World Bank (WB), An overview of Monitoring and Evaluation in the World Bank. Operations Evaluation Department, Washington D.C, USA (1994).

[3] C. Weiss, Methods for studying programs and policies, Weiss, London, Prentice Hall (1998).

[4] DG Regional Policy European Commission (DGRPEC), Guide to cost-benefit analysis of in-vestment projects. Evaluation Unit, 154 pp (2003).

[5] DG Regional Policy European Commission (DGRPEC), Guide to Cost-Benefit Analysis of In-vestment Projects: Economic appraisal tool for Cohesion Policy 20142020, 364 pp (2014).

[6] S. Shapiro, The Evolution of Cost-Benefit Analysis in U.S. Regulatory Decision making, Working Paper No.5, Jerusalem Papers in Regulation \& Governance, 23 pp (2010).

[7] Minnesota Department of Transportation (MDT), s/d - Benefit Cost Analysis. MN DOT Office of In-vestment Management (http://www.dot.state.mn.us/planning/program/benefitcost.html).

[8] E. Mishan, Cost-Benefit Analysis: An informal introduction. Fourth Edition, New York, Routledge (1994).

[9] CEPS, Assessing the costs and benefits of regulation, Study for the European Commission, Secretariat General, Brussel (2013).

[10] J. Raczka, The cost-effectiveness analysis - a superior alternative to the cost-benefit analysis of environmental infrastructure investments. 5th European Conference on Evaluation of the Structural Funds, "Challenges for Evaluation in an Enlarged Europe", Budapest 26/27 June (2003).

[11]G. Gauthier, T. Thibault, L'analyse cô̂ts-avantages, défis et controverses, HECCETAI, Economica (1993).

[12] European Comission (EC), Guide to cost benefit analysis of investment projects, Structural Funds, Cohesion Funs and Instrument for Pre-Accesion (2008).

[13] M.J. Falcão Silva, F. Salvado, Análise Custo Benefício: Metodologia para apoio à decisão em intervenções no setor da arquitetura, engenharia e construção. Relatório 288/2015-DED/NEG, Laboratório Nacional de Engenharia Civil (2015).

[14]F. Salvado, M.J. Falcão Silva, Aplicabilidade da metodologia de análise custobenefício: Identificação e proposta de avaliação de externalidade na reabilitação de edificios. Relatório 84/2016-DED/NEG, Laboratório Nacional de Engenharia Civil (2016).

[15] M.J. Falcão Silva, F. Salvado, Architectural heritage sustainable rehabilitation: Proposal for application of cost-benefit analysis. 41th IAHS World Congress on Housing - Sustainability and Innovation for the Future (41IAHS), 13-16 September, Albufeira, Portugal, Paper ID 497 (2016). 